\title{
First description of an acinic cell carcinoma of the breast in a BRCA1 mutation carrier: a case report
}

\author{
Carla B Ripamonti ${ }^{1}$, Mara Colombo ${ }^{1}$, Patrizia Mondini ${ }^{1}$, Manoukian Siranoush², Bernard Peissel ${ }^{2}$, Loris Bernard ${ }^{3,4}$, \\ Paolo Radice ${ }^{1,5^{*}}$ and Maria Luisa Carcangiu ${ }^{6}$
}

\begin{abstract}
Background: Acinic cell carcinoma (ACC) is a rare malignant epithelial neoplasm characterized by the presence of malignant tubular acinar exocrine gland structures. Diagnosis is generally made in salivary glands and in the pancreas. ACC of the breast has been reported in few cases only. Carriers of inherited mutations in the BRCA1 gene are prone to the development of breast cancer, mainly invasive ductal or medullary type carcinomas. We describe for the first time a BRCA1 mutation carrier with a diagnosis of ACC of the breast.

Case presentation: The patient developed an invasive ductal carcinoma (IDC) at the age of 40 years and an ACC in the contralateral breast at 44 years. Immunohistochemical examination of the ACC revealed a triple negative status (i.e., negativity for estrogen receptor, progesterone receptor and HER2 protein) and positivity for p53. Using a combination of loss of heterozygosity $(\mathrm{LOH})$ and sequencing analyses, the loss of the wild-type BRCA1 allele was detected in both the ACC and the IDC. In addition, two different somatic TP53 mutations, one in the ACC only and another one in the IDC only, were observed.

Conclusion: Both the immunohistochemical and molecular features observed in the ACC are typical of BRCA1associated breast cancers and suggest an involvement of the patient's germline mutation in the disease. The occurrence of rare histological types of breast cancers, including malignant phyllodes tumor, atypical medullary carcinoma and metaplastic carcinoma, in BRCA1 mutation carriers has been already reported. Our findings further broaden the spectrum of BRCA1-associated breast malignancies.
\end{abstract}

Keywords: Acinic cell carcinoma, Breast cancer, BRCA1, Triple negative, TP53 mutation

\section{Background}

Acinic cell carcinoma (ACC) is a rare histological type of malignant epithelial neoplasm exhibiting acinic cell differentiation. The typical locations are major and minor salivary glands and pancreas, where it accounts for approximately $10 \%$ and $1 \%$ of all cancers, respectively [1-3]. ACC has been occasionally observed in other organs, including lung, stomach, liver, retroperitoneum, lacrimal glands and breast [4-19]. ACC of the breast was first described by Roncaroli et al. in a 42-year-old woman who complained of a palpable lump that had rapidly increased in size and appeared at mammography as a well defined

\footnotetext{
* Correspondence: paolo.radice@istitutotumori.mi.it

${ }^{1}$ Unit of Molecular Bases of Genetic Risk and Genetic Testing, Department of Preventive and Predictive Medicine, Fondazione IRCCS Istituto Nazionale dei Tumori, Milan, Italy

${ }^{5}$ IFOM, Fondazione Istituto FIRC di Oncologia Molecolare, Milan, Italy

Full list of author information is available at the end of the article
}

lesion containing scattered granular calcifications [10]. Since then, a few additional cases have been reported in patients aged between 23 and 80 years, including a male subject [11-19]. Morphologically, ACC of the breast resembles the homonymous salivary gland tumor due to the formation of tubular acinar gland structures delimited by a thin layer of connective tissue. Two distinct patterns of growth have been described. The first is solid or nesting, poorly circumscribed and infiltrating, often accompanied by focal necrosis. The second pattern is characterized by the formation of acinar, tubular, microglandular and microcystic structures. The neoplastic cells are polygonal or round, with an amphophilic cytoplasm containing coarse brightly eosinophilic granules. The glandular lumina contain an amorphous eosinophilic material $[20,21]$.

Approximately $10 \%$ of breast cancers show a hereditary predisposition. It is estimated that nearly $20 \%$

\section{Biomed Central}


to $30 \%$ of these hereditary tumors are linked to germline mutations in either the BRCA1 or BRCA2 genes [22,23]. BRCA1 mutation carriers face a lifetime risk to develop breast cancer that ranges from $57 \%$ to $65 \%$ $[24,25]$. The pathological features of breast tumors arising in BRCA1 mutation carriers have been extensively described. They are mostly high grade invasive ductal not otherwise specified (NOS) or medullary type carcinomas. High mitotic index, pushing margins, lymphocytic infiltration and areas of necrosis are frequent findings. Immunoreactivity for estrogen receptor (ER), progesterone receptor (PgR) and for the human epidermal growth factor receptor 2 (HER2) is usually absent [26-28]. This profile, defined as "triple negative" (TN), has been shown to be highly predictive of the BRCA1 mutation carrier status [29].

$B R C A 1$ is a tumor suppressor gene involved in the control of cell cycle progression and of DNA double strand break (DSB) repair. The vast majority of breast tumors developing in BRCA1 carriers shows inactivation of the wild-type allele by either somatic genetic (mutations or loss of heterozygosity (LOH)) or epigenetic (promoter hypermethylation) changes [30]. These occurrences lead to the absence of functional BRCA1 protein and, thus, to genetic instability and tumor development. In addition, breast tumors in BRCA1 mutation carriers frequently show mutations of the TP53 gene and/or abnormal expression of the corresponding protein $\mathrm{p} 53$ [31,32].

In this study, we provide the first pathological, immunohistochemical and molecular characterization of a breast tumor of the ACC type developed in a BRCA1 mutation carrier.

\section{Case presentation}

\section{Clinical course and pathological features}

The patient is a 45-year-old woman with a familial history of breast and ovarian carcinomas and other cancers (Figure 1). Her mother died at the age of 50 years from ovarian cancer, and her maternal aunt developed breast cancer at 64 years and ovarian cancer at 72 years. The daughter of the latter patient died at 44 years from a metastatic malignant tumor, consistent with a salivary gland origin. Genetic testing of the patient's maternal aunt identified a constitutional BRCA1 mutation, c.4484 G>T, causing the skipping of exon $14[33,34]$. Subsequently, the presence of this mutation was ascertained in the subject of this report at the age of 36 years, when still in good health.

Following this finding, clinical examination and instrumental surveillance with mammography, magnetic resonance imaging (MRI) and ultrasonography were initiated according to the institutional protocols for BRCA gene mutation carriers. At the age of 40 years, a poorly differentiated invasive ductal carcinoma (IDC), measuring $25 \mathrm{~mm}$ in diameter, was diagnosed in the upper outer quadrant of the right breast. The pathology report described positive immunostaining for ER and PgR and negativity for HER2. A radical mastectomy with sentinel lymph node biopsy was performed. According to the pathological TNM (tumor, node, metastasis) staging system, the tumor was $\mathrm{pT} 2$, pN0. The patient received adjuvant chemotherapy with adriamycin, cyclophosphamide, methotrexate and 5-fluorouracil, and hormonal therapy with tamoxifen and luteinizing-hormonereleasing hormone (LH-RH) analogue. At the age of 41 years, two left axillary lymph nodes were biopsied

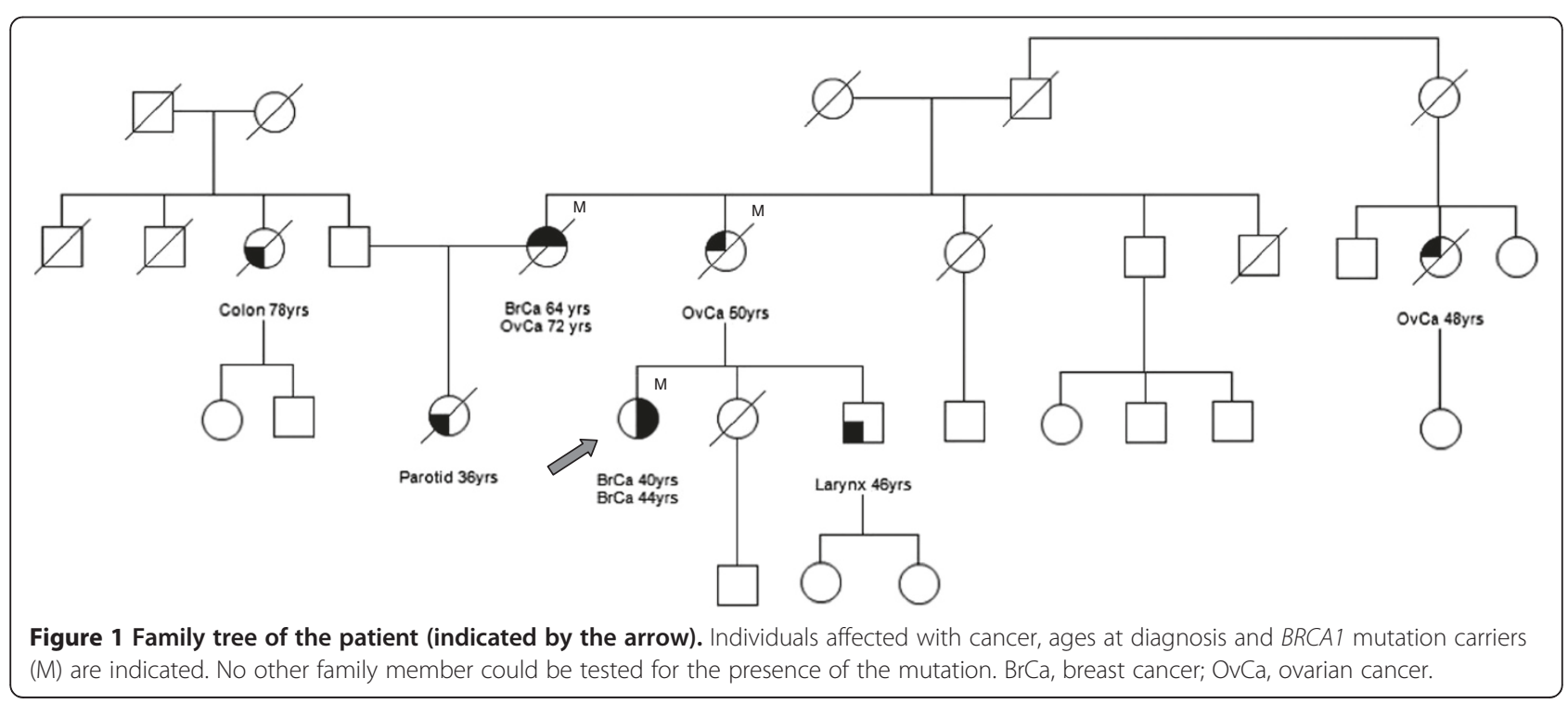


and reported as reactive and negative for metastatic tumor. One year later, the patient underwent prophylactic salpingo-oophorectomy and the LH-RH analogue was stopped, whereas the tamoxifen therapy was switched to aromatase inhibitors.

At the age of 44 years, a breast MRI revealed a solid mass with pushing margins in the upper outer quadrant of the left breast. A mammary resection (lumpectomy) was carried out, and the histological diagnosis was made of ACC with a microglandular pattern of growth. On gross examination, the tumor appeared as an ill-defined yellowish firm area measuring $13 \mathrm{~mm}$ in its largest dimension. Microscopically, it was characterized by a diffuse tightly packed proliferation of small acinar and glandular structures, frequently intermixed with solid nests of markedly eosinophilic larger cells. The acinar and glandular structures were made of round cells with a finely granular, weakly basophilic, or clear cytoplasm resembling those of acinar cells of salivary glands. The eosinophilic cells showed bright eosinophilic coarse granules resembling those of intestinal Paneth cells (Figure 2A,B).

Immunohistochemical stainings were performed using the streptavidin-biotin peroxidase method, in accordance with the manufacturer's instructions (Table 1). The neoplastic cells were immunohistochemically positive for the S100 protein, epithelial membrane antigen (EMA), p53 (Figure 2C) and alpha-1-antichymotrypsin (AACT) whereas maspin, gross cystic disease fluid protein-15 (GCDFP), ER, PgR and HER2 were negative. Immunostains for actin and calponin did not show myoepithelial differentiation.

Two months later, a radical mastectomy was performed. No residual tumor was found in the remaining parenchymal tissue or in the two microscopically examined lymph nodes. The patient is alive and well 19 months after the surgery, with no evidence of disease and still undergoing hormonal therapy.

A written consent approved by the Ethical Committee of the Fondazione IRCCS Istituto Nazionale dei Tumori, was obtained from the patient to the use of her biological samples for research purposes.

\section{Genetic investigations}

Formaldehyde-fixed, paraffin-embedded surgical specimens of both the ACC and the IDC were retrieved and reviewed by the pathologist. Tumor areas were manually microdissected. DNA was extracted from tumor and normal (peripheral blood leukocytes; PBLs) tissues using commercial kits (QIAGEN). The region corresponding to the BRCA1-associated D17S855 polymorphic microsatellite marker was amplified by polymerase chain reaction (PCR) from the ACC and normal DNA, using a $5^{\prime}$ end fluorescent dye labeled forward primer (VWR

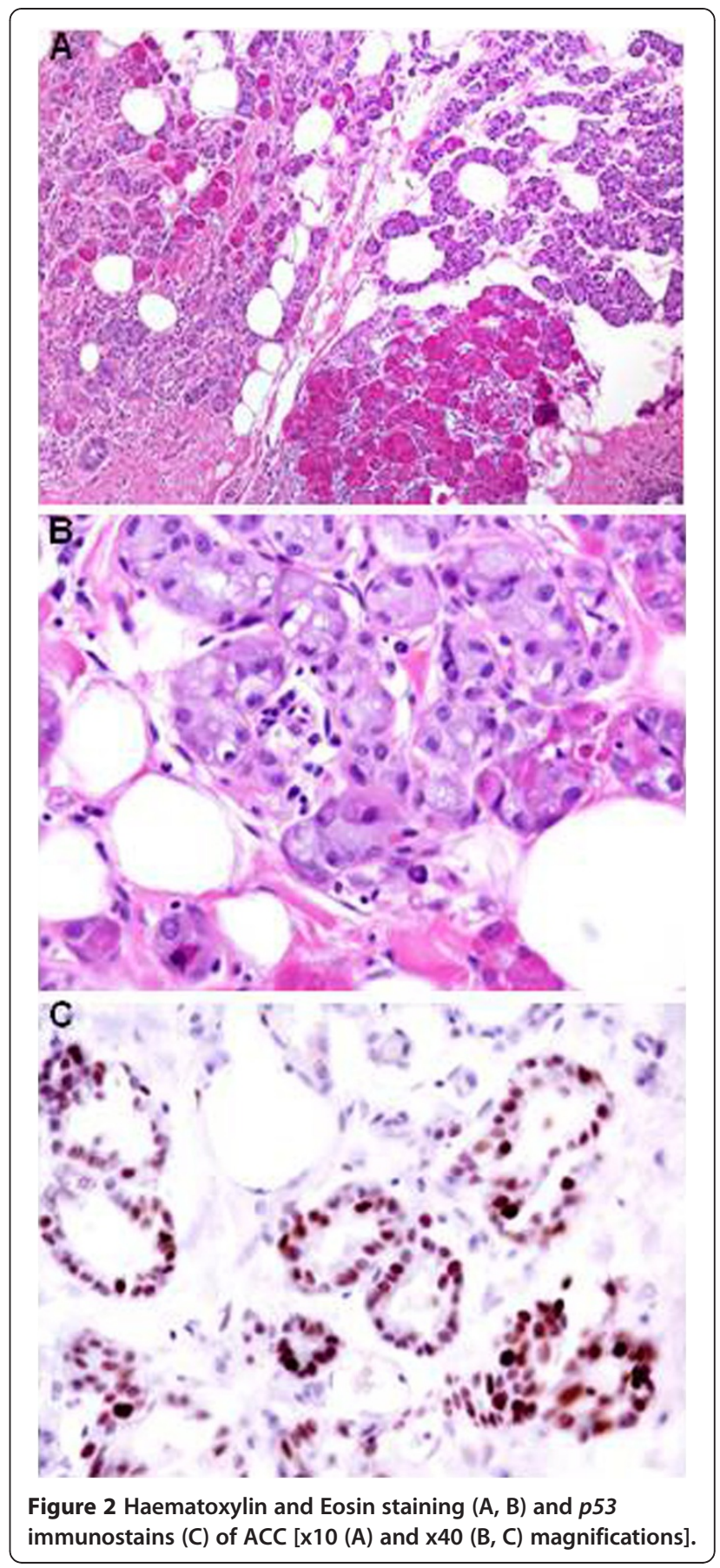

International). The amplification products were separated by capillary electrophoresis on an ABI 3130 Genetic Analyzer (Applied Biosystems) and analyzed using the Gene Mapper 4.0 software (Applied Biosystems). The ratio between the peak area of the larger allele and that of the smaller allele in tumor DNA (Figure 3B) was calculated after normalization on the corresponding ratio in the normal DNA (Figure 3A). LOH was assessed in the tumor sample where a strong reduction (ca. 70\%) 
Table 1 Primary antibodies and dilutions used for the immunohistochemical analyses and results

\begin{tabular}{lccc}
\hline Antibody to & Manufacturer & Dilution & Results \\
\hline ER & Ventana & ready-to-use & Negative \\
PgR & Ventana & ready-to-use & Negative \\
HER2 & Dako & $1: 1000$ & Negative \\
S100 protein & Dako & $1: 2000$ & Positive \\
EMA & Ventana & ready-to-use & Positive \\
GCDFP15 & Signet & $1: 20$ & Negative \\
P53 & Novocastra & $1: 200$ & Positive \\
AACT & Dako & $1: 1000$ & Positive \\
Actin & Dako & $1: 400$ & Negative \\
Maspin & Pharmingen & $1: 500$ & Negative \\
Calponin & BioGenex & $1: 400$ & Negative \\
\hline ER estron & PgR & progestere & HER2 huma epder
\end{tabular}

ER, estrogen receptor; PgR, progesterone receptor; HER2, human epidermal growth factor receptor 2; EMA, epithelial membrane antigen; GCDFP15, gross cystic disease fluid protein-15; AACT, alpha-1-antichymotrypsin.

of the peak ratio was observed as compared to normal DNA. To evaluate which BRCA1 allele was lost, we performed the sequence analysis of the genomic region encompassing the BRCA1 constitutional mutation in normal and ACC DNA. The sequence reactions were performed with the ABI PRISM ${ }^{\circledR}$ Big Dye Terminator Cycle Sequencing Kit (Applied Biosystems), run on an ABI 3130 Genetic Analyzer and examined using the Sequencing Analysis Software (Applied Biosystems). A strong reduction of the constitutionally wild-type allele (G) was observed in the ACC (Figure 3E), compared to normal DNA (Figure 3D). Therefore, the ACC presented a bi-allelic inactivation of the $B R C A 1$ gene due to the constitutional mutation coupled with the somatic loss of the wild-type allele.

The sequencing of coding exons (2 to 11) of the TP53 gene in the ACC identified the c.654_655insGTG mutation (Figure 4B), which was not present in the normal DNA (Figure 4A). This mutation was previously described in a case of Burkitt lymphoma [35].

Using the above described approaches, loss of the wild-type BRCA1 allele (Figures 3C, 3F) and a TP53 mutation (c.994-1 G>A) (Figure 4F) were also observed in the IDC sample. The TP53 mutation was not present in both the normal (Figure 4D) and the ACC (Figure 4E) DNA. Conversely, the TP53 mutation observed in the ACC was absent in the IDC (Figure 4C).

\section{Discussion}

A few studies have recently documented the occurrence of ACCs in patients with hereditary susceptibility to cancer. Five reports have been published describing the development of ACCs of the pancreas in subjects carrying germline mutations in genes predisposing to breast and colon cancers. More specifically, a pancreatic ACC was reported in a BRCA1 male mutation carrier with a family history positive for early-onset breast cancers. The proband had a previous history of papillary renal and colon cancers and was affected with acromegaly [36]. Skoulidis et al. described ACCs of the pancreas in three subjects with $B R C A 2$ germline mutations and detected $\mathrm{LOH}$ at the BRCA2 locus in the tumors [37]. Furthermore, the diagnosis of pancreatic ACC was made in a 46-year-old male affected with liposarcoma, polyps and hamartomas of the colon, who carried a germline

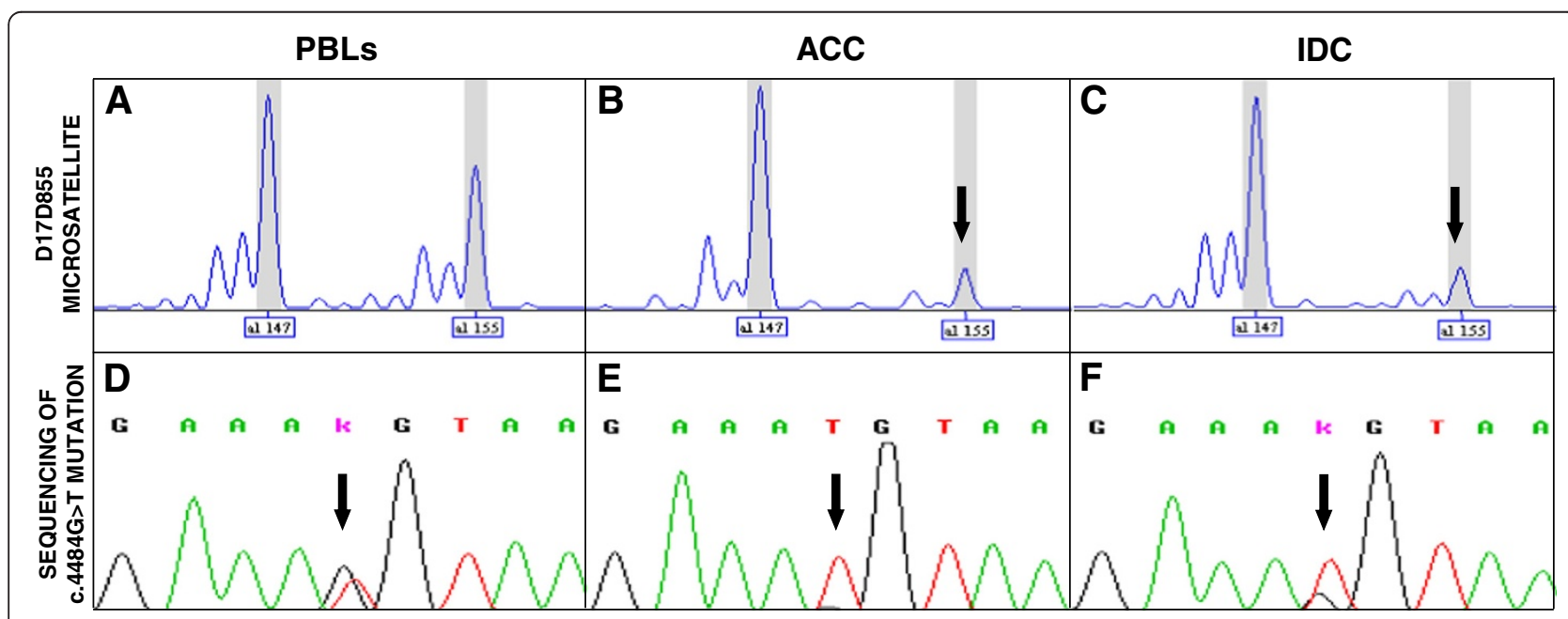

Figure 3 Assessment of the loss of the wild-type BRCA1 allele in tumor DNA. A-C) The two D175855 alleles (al_147 and al_155) present in the peripheral blood leukocytes (PBLs) DNA of the patient are indicated. A strong reduction of the peak corresponding to the al_155 allele is observed in both the ACC and the IDC DNA (indicated by the arrows). D-F) BRCA1 sequence analysis. The site of the germline c.4484 G>T mutation is indicated by the arrows. A reduction of the wild-type $G$ allele is visible in both the ACC and IDC DNA. 


\section{c.654_655insGTG c.994 -1G>A}

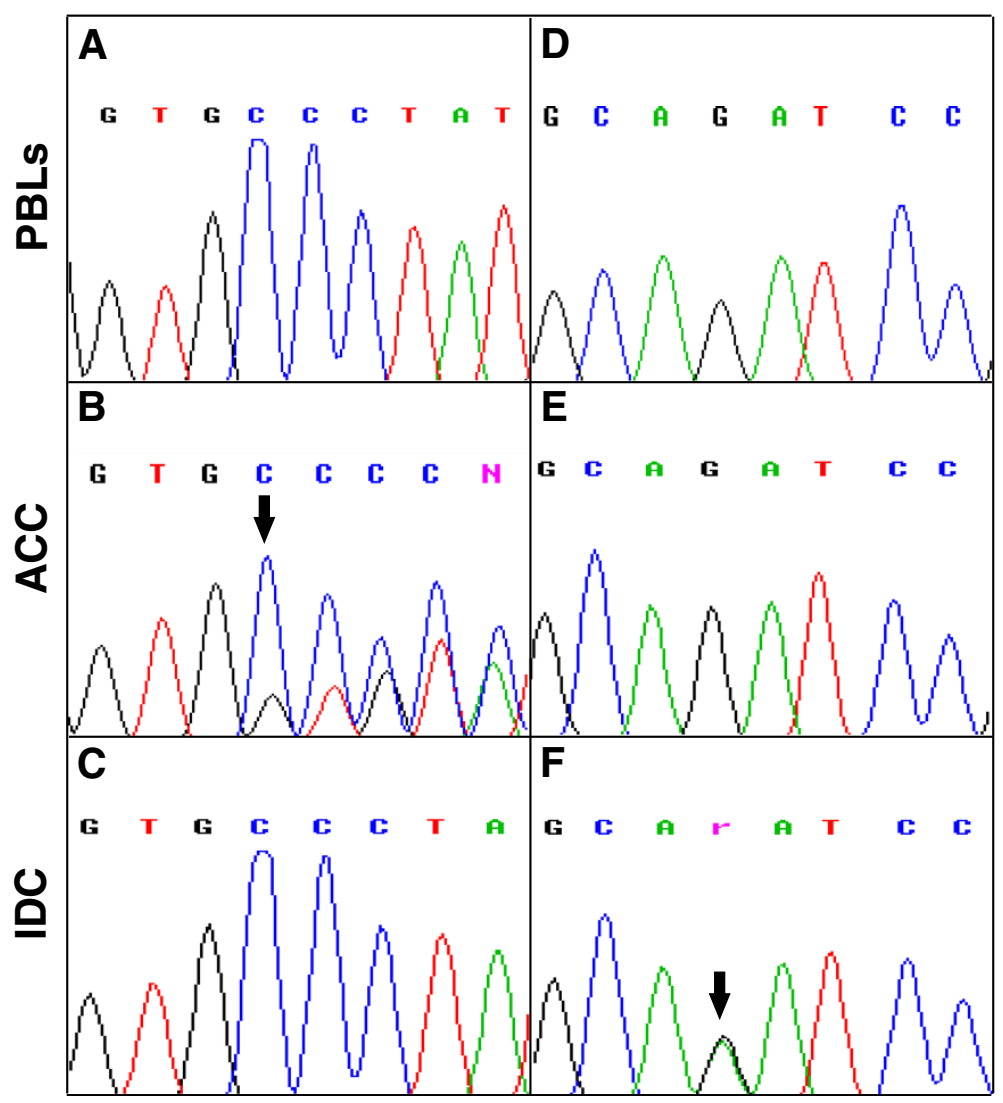

Figure 4 TP53 sequence analysis. A-C) DNA sequences showing the presence of the c.654_655insGTG mutation in the ACC and its absence in the IDC and PBL DNA. D-F) DNA sequences showing the presence of the c.994-1 G>A mutation in the ICD and its absence in the ACC and PBL DNA. The position of the mutations is indicated by the arrows. PBLs, peripheral blood leukocytes.

mutation in $S T K 11 / L K B$, the gene causing the PeutzJeghers syndrome. By LOH analysis, the authors assessed a link between the loss of the wild-type STK11/LKB1 allele and the onset of the ACC [38]. Interestingly, no STK11/LKB1 mutation or altered RNA expression were, by contrast, found in five sporadic ACCs of the pancreas [39]. A metastatic ACC of the pancreas was described in a female patient carrying a mutation in MSH6, one of the genes responsible for the Lynch syndrome. The patient had received previous diagnoses of invasive breast cancer, and sebaceous and basal cell carcinomas of the skin [40]. Finally, germline mutations of PRKAR1A, the gene responsible for the Carney complex, were observed in two patients with pancreatic ACCs. $\mathrm{LOH}$ at the gene locus and absence of the corresponding protein expression were observed in tumor cells [41].

An ACC of the retromolar trigone region was described in a 35-year-old patient with a clinical diagnosis of Cowden disease and a genetic analysis positive for a pathogenic mutation in PTEN [42]. Cowden disease is characterized by the presence of multiple hamartomas, a type of malformation mainly affecting the gastrointestinal tract, and an increased susceptibility to breast, thyroid and endometrial cancers [43].

To the best of our knowledge, our report is the first describing a primary ACC of the mammary gland in a BRCA1 mutation carrier. Histologically, the tumor displayed two populations, one characterized by a microglandular pattern of growth and the other consisting of solid nests of cells. The glandular cells were characterized by basophilic cytoplasm, while the latter showed eosinophilic cytoplasmic granules. The results of immunohistochemical analysis were in accordance with previous reports and confirmed the diagnosis of ACC [11-19]. In addition, the tumor exhibited a TN phenotype, in agreement with four out of the five previous reports of ACCs of the breast for which the results of ER, PgR and HER2 stains were available [13,15,17-19].

Molecular characterization detected the loss of the BRCA1 wild-type allele and a TP53 somatic mutation in tumor DNA. The involvement of TP53 in tumor development was confirmed by immunohistochemistry that showed 
positivity for $\mathrm{p} 53$. By contrast, the only previously reported ACC of the breast that had been examined for p53 expression tested negative on immunostaining [13]. We also investigated for LOH at BRCA1 locus and for TP53 mutations the DNA extracted from the IDC that the patient had developed few years before the diagnosis of ACC. Like the ACC, the IDC displayed loss of the BRCA1 wild type allele and the somatic TP53 mutation. However, this mutation was different from the one detected in the ACC, indicating a diverse origin of the two tumors. Our results are consistent with the observation that somatic alterations of BRCA1 and TP53 are frequent in breast cancers, particularly those of the TN phenotype $[44,45]$. Both genes are key players in the control of DNA damage response and their impairment leads to tumor development by inducing, among other mechanisms, genomic instability.

Our findings are consistent with previous studies reporting $\mathrm{LOH}$ at BRCA1 locus and TP53 abnormalities as frequent events in breast cancers occurring in $B R C A 1$ mutation carriers [31,32]. Therefore, we may argue a causal role of the genetic background of the patient, which made her prone to breast cancer, not only in the development of the IDC, but also in the rare phenotypic expression of the ACC. Interestingly, a considerable proportion $(7 / 14=50 \%)$ of the previously documented cases of ACC of the breast were of early-onset (age at diagnosis $<50$ years) $[10-12,14-16,18]$. This observation suggests the involvement of hereditary factors in at least a fraction of these patients.

Atypical and unusual histologic features of breast cancers in BRCA1 mutation carriers have been reported. A malignant phyllodes tumor was observed in a 43years-old patient, who tested positive for the c.5095C>T (p.R1699W) missense pathogenic mutation [34,46]. In addition, Ashida et al. reported an atypical medullary carcinoma of the breast with cartilaginous metaplasia in a young patient with a nonsense mutation in exon 5 [47]. The association of BRCA1 mutations with other histotypes, commonly grouped under the term of metaplastic breast carcinomas (MBC) and including squamous, adenosquamous and tumors with biphasic morphology carcinomas (so-called carcinosarcomas), was also described. Breuer et al. reported on a young woman, carrying the c.181 T>G (p.C61G) mutation, who had developed bilateral asynchronous squamous breast cancers at 25 and at 28 years of age [48]. Suspitsin et al. described a mixed epithelial/mesenchimal metaplastic carcinoma that was diagnosed in a 35-year-old female carrier of the c.5266dupC mutation. The molecular analysis revealed the loss of the wild-type $B R C A 1$ allele in both the epithelial and the mesenchymal components of the tumor, supporting the role of BRCA1 in its development [49]. A low-grade adenosquamous carcinoma of the breast described by Noel et al. was diagnosed in a 49-year-old woman with a previous diagnosis of IDC and the presence of the c.66dupA mutation [50]. Finally, Rashid et al. reported a biphasic carcinoma composed of sarcomatous and malignant epithelial components in a 22-year-old proband who carried the c.68_69delAG mutation [51]. With the single exception of the study of Suspitsin et al., the above mentioned reports described a "basal like" phenotype of the tumor tissues, on the basis of the TN status and the positivity by immunohystochemistry of the basal cytokeratin CK5/6. In fact, the majority of BRCA1-related breast cancers express basal cytokeratins [27] and the discovery of this status in the $\mathrm{MBCs}$ reported to date is in favor of the involvement of $B R C A 1$ in the tumor development.

\section{Conclusions}

We described the first case of a $B R C A 1$ mutation carrier affected with an ACC of the breast, a very rare histological subtype of mammary tumor. Immunohistochemical analyses and molecular investigations of the ACC provided evidences suggestive of an involvement of the constitutional BRCA1 mutation in the pathogenesis of disease. In addition to the present case, studies reporting on malignant phyllodes tumor, atypical medullary carcinoma and MBCs of the breast support the notion that rare histological types of breast cancers can occur in patients with mutations in BRCA1 and that their development is mediated by the presence of such mutations. Further studies are needed to understand which additional factors contribute to make $B R C A 1$ mutation carriers prone to the expression of different breast tumor phenotypes.

\section{Consent}

Written informed consent was obtained from the patient for publication of this Case report and any accompanying images. A copy of the written consent is available for review by the Editor of this journal.

\section{Competing interests}

The authors declare that they have no competing interests.

\section{Authors' contributions}

RCB designed the study, carried out the molecular analyses and drafted the manuscript. CM helped to perform the sequencing analyses and to draw the figures. MP provided technical support. MS and PB retrieved and provided the clinical data. BL performed the BRCA1 mutation screening. RP provided the final editing and approval of the manuscript for publishing. CML made the histological diagnosis, performed the immunohistochemical analyses and contributed to the writing of the manuscript. All authors read and approved the final manuscript.

\section{Acknowledgments}

The study was supported by a grant from Associazione Italiana per la Ricerca sul Cancro (AIRC).

\section{Author details}

'Unit of Molecular Bases of Genetic Risk and Genetic Testing, Department of Preventive and Predictive Medicine, Fondazione IRCCS Istituto Nazionale dei 
Tumori, Milan, Italy. ${ }^{2}$ Unit of Medical Genetics, Department of Preventive and Predictive Medicine, Fondazione IRCCS Istituto Nazionale dei Tumori, Milan, Italy. ${ }^{3}$ Division of Experimental Oncology, Istituto Europeo di Oncologia, Milan, Italy. ${ }^{4}$ Cogentech, Cancer Genetic Test Laboratory, IFOM-IEO Campus, Milan, Italy. ${ }^{5} \mathrm{FOM}$, Fondazione Istituto FIRC di Oncologia Molecolare, Milan, Italy. ${ }^{6}$ Anatomic Pathology Unit 1, Department of Pathology and Laboratory Medicine, Fondazione IRCCS Istituto Nazionale dei Tumori, Milan, Italy.

Received: 5 September 2012 Accepted: 30 January 2013

Published: 1 February 2013

\section{References}

1. Hoffman HT, Karnell LH, Robinson RA, Pinkston JA, Menck HR: National cancer data base report on cancer of the head and neck: acinic cell carcinoma. Head Neck 1999, 21:297-309.

2. Ordóñez NG: Pancreatic acinar cell carcinoma. Adv Anat Pathol 2001, 8:144-159.

3. Holen KD, Klimstra DS, Hummer A, Gonen M, Conlon K, Brennan M, Saltz LB: Clinical characteristics and outcomes from an institutional series of acinar cell carcinoma of the pancreas and related tumors. $J$ Clin Oncol 2002, 15:4673-4678.

4. De Rosa G, Zeppa P, Tranfa F, Bonavolontà G: Acinic cell carcinoma arising in a lacrimal gland. First case report. Cancer 1988, 57:1988-1891.

5. Rodriguez J, Diment J, Lombardi L, Dominoni F, Tench W, Rosai J: Combined typical carcinoid and acinic cell tumor of the lung: a heretofore unreported occurrence. Hum Pathol 2003, 34:1061-1065.

6. Hervieu V, Lombard-Bohas C, Dumortier J, Boillot O, Scoazec JY: Primary acinar cell carcinoma of the liver. Virchows Arch 2008, 452:337-341.

7. Ambrosini-Spaltro A, Potì O, De Palma M, Filotico M: Pancreatic-type acinar cell carcinoma of the stomach beneath a focus of pancreatic metaplasia of the gastric mucosa. Hum Pathol 2009, 40:746-749.

8. Agaimy A, Kaiser A, Becker K, Bräsen JH, Wünsch PH, Adsay NV, Klöppel G: Pancreatic-type acinar cell carcinoma of the liver: a clinicopathologic study of four patients. Mod Pathol 2011, 24:1620-1626.

9. Pesci A, Castelli P, Facci E, Romano L, Zamboni G: Primary retroperitoneal acinar cell cystadenoma. Hum Pathol 2012, 43:446-450.

10. Roncaroli F, Lamovec J, Zidar A, Eusebi V: Acinic cell-like carcinoma of the breast. Virchows Arch 1996, 429:69-74.

11. Shimao K, Haga S, Shimizu T, Imamura H, Watanabe O, Kinoshita J, Nagumo H, Utada Y, Okabe T, Kajiwara T, Oshibe N, Aiba M: Acinic cell adenocarcinoma arising in the breast of a young male: a clinicopathological. Immunohistochemical and ultrastructural study. Breast Cancer 1998, 5:77-81.

12. Damiani S, Pasquinelli G, Lamovec J, Peterse JL, Eusebi V: Acinic cell carcinoma of the breast: an immunohistochemical and ultrastructural study. Virchows Arch 2000, 437:74-81.

13. Schmitt FC, Ribeiro CA, Alvarenga S, Lopes JM: Primary acinic cell-like carcinoma of the breast-a variant with good prognosis? Histopathology 2000, 3:286-289.

14. Coyne JD, Dervan PA: Primary acinic cell carcinoma of the breast. J Clin Pathol 2002, 55:545-547.

15. Elster EA, Markusic J, Ball R, Soballe P, Henry M, Louie A, Clare S: Primary acinic cell carcinoma of the breast. Am Surg 2002, 68:993-995.

16. Peintinger F, Leibl S, Reitsamer R, Moinfar F: Primary acinic cell carcinoma of the breast: a case report with long-term follow-up and review of the literature. Histopathology 2004, 45:645-648.

17. Tanahashi C, Yabuki S, Akamine N, Yatabe Y, Ichihara S: Pure acinic cell carcinoma of the breast in an 80-year-old Japanese woman. Pathol Int 2007, 57:43-46.

18. Chang ED, Lee EJ, Lee AW, Kim JS, Kang CS: Primary acinic cell carcinoma of the breast: a case report with an immunohistochemical and ultrastructural studies. J Breast Cancer 2011, 14:160-164.

19. Sakuma T, Mimura A, Tanigawa N, Takamizu R: Fine needle aspiration cytology of acinic cell carcinoma of the breast. Cytopathology 2012, doi:10.1111/j.1365-2303.2012.00996.x. Epub ahead of print.

20. Pia-Foschini M, Reis-Filho JS, Eusebi V, Lakhani SR: Salivary gland-like tumours of the breast: surgical and molecular pathology. J Clin Pathol 2003, 56:497-506.

21. Foschini MP, Krausz T: Salivary gland-type tumors of the breast: a spectrum of benign and malignant tumors including "triple negative carcinomas" of low malignant potential. Semin Diagn Pathol 2010, 27:77-90.

22. Stratton MR, Rahman N: The emerging landscape of breast cancer susceptibility. Nat Genet 2008, 40:17-22.

23. Mavaddat N, Rebbeck TR, Lakhani SR, Easton DF, Antoniou AC Incorporating tumour pathology information into breast cancer risk prediction algorithms. Breast Cancer Res 2010, 12:R28.

24. Antoniou A, Pharoah PD, Narod S, Risch HA, Eyfjord JE, Hopper JL, Loman N, Olsson H, Johannsson O, Borg A, Pasini B, Radice P, Manoukian S, Eccles DM, Tang N, Olah E, Anton-Culver H, Warner E, Lubinski J, Gronwald J, Gorski B, Tulinius H, Thorlacius S, Eerola H, Nevanlinna H, Syrjäkoski K, Kallioniemi OP, Thompson D, Evans C, Peto J, et al: Average risks of breast and ovarian cancer associated with BRCA1 or BRCA2 mutations detected in case Series unselected for family history: a combined analysis of 22 studies. Am J Hum Genet 2003, 72:1117-1130.

25. Chen S, Parmigiani G: Meta-analysis of BRCA1 and BRCA2 penetrance. J Clin Oncol 2007, 25:1329-1333.

26. Lakhani SR, Van De Vijver MJ, Jacquemier J, Anderson TJ, Osin PP, McGuffog L, Easton DF: The pathology of familial breast cancer: predictive value of immunohistochemical markers estrogen receptor, progesterone receptor, HER-2, and p53 in patients with mutations in BRCA1 and BRCA2. J Clin Oncol 2002, 20:2310-2318.

27. Lakhani SR, Reis-Filho JS, Fulford L, Penault-Llorca F, van der Vijver M, Parry S, Bishop T, Benitez J, Rivas C, Bignon YJ, Chang-Claude J, Hamann U, Cornelisse CJ, Devilee P, Beckmann MW, Nestle-Krämling C, Daly PA, Haites N, Varley J, Lalloo F, Evans G, Maugard C, Meijers-Heijboer H, Klijn JG, Olah E, Gusterson BA, Pilotti S, Radice P, Scherneck S, Sobol H, et al: Prediction of BRCA1 status in patients with breast cancer using estrogen receptor and basal phenotype. Clin Cancer Res 2005, 11:5175-5180.

28. Palacios J, Honrado E, Osorio A, Cazorla A, Sarrió D, Barroso A, Rodríguez S, Cigudosa JC, Diez O, Alonso C, Lerma E, Dopazo J, Rivas C, Benítez J: Phenotypic characterization of BRCA1 and BRCA2 tumors based in a tissue microarray study with 37 immunohistochemical markers. Breast Cancer Res Treat 2005, 90:5-14.

29. Mavaddat N, Barrowdale D, Andrulis IL, Domchek SM, Eccles D, Nevanlinna H, Ramus SJ, Spurdle A, Robson M, Sherman M, Mulligan AM, Couch FJ, Engel C, McGuffog L: Consortium of Investigators of Modifiers of BRCA1/ 2: Pathology of breast and ovarian cancers among BRCA1 and BRCA2 mutation carriers: results from the Consortium of Investigators of Modifiers of BRCA1/2 (CIMBA). Cancer Epidemiol Biomarkers Prev 2012, 21:134-147.

30. Honrado E, Benítez J, Palacios J: The molecular pathology of hereditary breast cancer: genetic testing and therapeutic implications. Mod Pathol 2005, 18:1305-1320.

31. Greenblatt MS, Chappuis PO, Bond JP, Hamel N, Foulkes WD: TP53 mutations in breast cancer associated with BRCA1 or BRCA2 germ-line mutations: distinctive spectrum and structural distribution. Cancer Res 2001, 61:4092-4097.

32. Colombo M, Giarola M, Mariani L, Ripamonti CB, De Benedetti V, Sardella M, Losa M, Manoukian S, Peissel B, Pierotti MA, Pilotti S, Radice P: Cyclin D1 expression analysis in familial breast cancers may discriminate BRCAX from BRCA2-linked cases. Mod Pathol 2008, 21:1262-1270.

33. Yang Y, Swaminathan S, Martin BK, Sharan SK: Aberrant splicing induced by missense mutations in BRCA1: clues from a humanized mouse model. Hum Mol Genet 2003, 12:2121-2131.

34. Easton DF, Deffenbaugh AM, Pruss D, Frye C, Wenstrup RJ, Allen-Brady K Tavtigian SV, Monteiro AN, Iversen ES, Couch FJ, Goldgar DE: A systematic genetic assessment of 1,433 sequence variants of unknown clinical significance in the BRCA1 and BRCA2 breast cancer-predisposition genes. Am J Hum Genet 2007, 8:873-883.

35. Petitjean A, Mathe E, Kato S, Ishioka C, Tavtigian SV, Hainaut P, Olivier M: Impact of mutant p53 functional properties on TP53 mutation patterns and tumor phenotype: lessons from recent developments in the IARC TP53 database. Hum Mutat 2007, 28:622-629.

36. Lowery MA, Kelsen DP, Stadler ZK, Yu KH, Janjigian YY, Ludwig E, D'Adamo DR, Salo-Mullen E, Robson ME, Allen PJ, Kurtz RC, O'Reilly EM: An emerging entity: pancreatic adenocarcinoma associated with a known BRCA mutation: clinical descriptors, treatment implications, and future directions. Oncologist 2011, 16:1397-1402.

37. Skoulidis F, Cassidy LD, Pisupati V, Jonasson JG, Bjarnason H, Eyfjord JE, Karreth FA, Lim M, Barber LM, Clatworthy SA, Davies SE, Olive KP, Tuveson 
DA, Venkitaraman AR: Germline Brca2 heterozygosity promotes Kras (G12D)-driven carcinogenesis in a murine model of familial pancreatic cancer. Cancer Cell 2010, 18:499-509.

38. Klümpen HJ, Queiroz KC, Spek CA, van Noesel CJ, Brink HC, de Leng WW, de Wilde RF, Mathus-Vliegen EM, Offerhaus GJ, Alleman MA, Westermann AM, Richel DJ: mTOR inhibitor treatment of pancreatic cancer in a patient With Peutz-Jeghers syndrome. J Clin Oncol 2011, 29:e150-153.

39. de Wilde RF, Ottenhof NA, Jansen M, Morsink FH, de Leng WW, Offerhaus GJ, Brosens LA: Analysis of LKB1 mutations and other molecular alterations in pancreatic acinar cell carcinoma. Mod Pathol 2011, 24:1229-1236. doi:10.1038/modpathol.2011.83.

40. Lowery MA, Klimstra DS, Shia J, Yu KH, Allen PJ, Brennan MF, O'Reilly EM: Acinar cell carcinoma of the pancreas: new genetic and treatment insights into a rare malignancy. Oncologist 2011, 16:1714-1720.

41. Gaujoux S, Tissier F, Ragazzon B, Rebours V, Saloustros E, Perlemoine K, Vincent-Dejean C, Meurette G, Cassagnau E, Dousset B, Bertagna X, Horvath A, Terris B, Carney JA, Stratakis CA, Bertherat J: Pancreatic ductal and acinar cell neoplasms in Carney complex: a possible new association. J Clin Endocrinol Metab 2011, 96:E1888-1895.

42. Villeneuve H, Tremblay S, Galiatsatos P, Hamel N, Guertin L, Morency R, Tischkowitz $\mathrm{M}$ : Acinic cell carcinoma of the retromolar trigone region: expanding the tumor phenotype in Cowden syndrome? Fam Cancer 2011, 10:691-694.

43. Farooq A, Walker LJ, Bowling J, Audisio RA: Cowden syndrome. Cancer Treat Rev 2010, 36:577-583.

44. Walerych D, Napoli M, Collavin L, Del Sal G: The rebel angel: mutant p53 as the driving oncogene in breast cancer. Carcinogenesis 2012, 33:2007-17.

45. Santarosa M, Maestro R: BRACking news on triple-negative/basal-like breast cancers: how BRCA1 deficiency may result in the development of a selective tumor subtype. Cancer Metastasis Rev 2012, 31:131-42.

46. Rhiem K, Flucke U, Engel C, Wappenschmidt B, Reinecke-Lüthge A, Büttner R, Schmutzler RK: Association of the BRCA1 missense variant R1699W with a malignant phyllodes tumor of the breast. Cancer Genet Cytogenet 2007, 176:76-79.

47. Ashida A, Fukutomi T, Tsuda H, Akashi-Tanaka S, Ushijima T: Atypical medullary carcinoma of the breast with cartilaginous metaplasia in a patient with a BRCA1 germline mutation. Jpn J Clin Oncol 2000, 30:30-32.

48. Breuer A, Kandel M, Fisseler-Eckhoff A, Sutter C, Schwaab E, Lück HJ, du Bois A: BRCA1 germline mutation in a woman with metaplastic squamous cell breast cancer. Onkologie 2007, 30:316-318.

49. Suspitsin EN, Sokolenko AP, Voskresenskiy DA, Ivantsov AO, Shelehova KV, Klimashevskiy VF: Mixed epithelial/mesenchymal metaplastic carcinoma (carcinosarcoma) of the breast in BRCA1 carrier. Breast Cancer 2011, 18:137-140.

50. Noël JC, Buxant F, Engohan-Aloghe C: Low-grade adenosquamous carcinoma of the breast-a case report with a BRCA1 germline mutation. Pathol Res Pract 2010, 206:511-513.

51. Rashid MU, Shah MA, Azhar R, Syed AA, Amin A, Hamann U: A deleterious BRCA1 mutation in a young Pakistani woman with metaplastic breast carcinoma. Pathol Res Pract 2011, 207:583-586.

doi:10.1186/1471-2407-13-46

Cite this article as: Ripamonti et al:: First description of an acinic cell carcinoma of the breast in a BRCA1 mutation carrier: a case report. BMC Cancer 2013 13:46.

\section{Submit your next manuscript to BioMed Central and take full advantage of:}

- Convenient online submission

- Thorough peer review

- No space constraints or color figure charges

- Immediate publication on acceptance

- Inclusion in PubMed, CAS, Scopus and Google Scholar

- Research which is freely available for redistribution 